\title{
THE USE OF REMOTE SENSING DATA FOR MODELING AIR QUALITY IN THE CITIES
}

\author{
V. V. Putrenko ${ }^{1}$, N.M. Pashynska ${ }^{2}$ \\ ${ }^{1}$ World Data Center for Geoinformatics and Sustainable Development, Igor Sikorsky KPI Kyiv, Ukraine - \\ putrenko@wdc.org.ua \\ ${ }^{2}$ Department of intellectual and information systems Taras Shevchenko National University of Kyiv, Ukraine - pashynska@ukr.net
}

\author{
Commission V, WG V/7
}

KEY WORDS: monitoring, pollution, remote sensing data, regression model, Ukraine, nitrogen dioxide, PM2.5

\begin{abstract}
:
Monitoring of environmental pollution in the cities by the methods of remote sensing of the Earth is actual area of research for sustainable development. Ukraine has a poorly developed network of monitoring stations for air quality, the technical condition of which is deteriorating in recent years. Therefore, the possibility of obtaining data about the condition of air by remote sensing methods is of great importance. The paper considers the possibility of using the data about condition of atmosphere of the project AERONET to assess the air quality in Ukraine. The main pollution indicators were used data on fine particulate matter (PM2.5) and nitrogen dioxide (NO2) content in the atmosphere. The main indicator of air quality in Ukraine is the air pollution index (API). We have built regression models the relationship between indicators of $\mathrm{NO} 2$, which are measured by remote sensing methods and ground-based measurements of indicators. There have also been built regression models, the relationship between the data given to the land of NO2 and API. To simulate the relationship between the API and PM2.5 were used geographically weighted regression model, which allows to take into account the territorial differentiation between these indicators. As a result, the maps that show the distribution of the main types of pollution in the territory of Ukraine, were constructed. PM2.5 data modeling is complicated with using existing indicators, which requires a separate organization observation network for PM2.5 content in the atmosphere for sustainable development in cities of Ukraine.
\end{abstract}

\section{INTRODUCTION}

\subsection{General Instructions}

The problems of air pollution are important and actual to support sustainable development and clean environment. The problem of evaluating air quality is especially actual for Ukraine due to the large amount of emissions from stationary and non-stationary pollution sources and low level development of a system observations in cities. Therefore, the use of remote sensing (RS) provides advantages for monitoring air quality in the entire country by a wide territorial coverage and low cost, but the use of RS data necessary to conduct complex work on verification and comparison with ground-based measurements tool.

Today in Ukraine there are about 50 posts of complex monitoring of the ecological state of air. This is not enough to control air quality in the country as a whole. Having found out the links between observations at the posts and the values of remote sensing data, we can predict with high accuracy the different kinds of pollution and obtain total estimates throughout the country.

\section{BACKGROUND}

Nitrogen dioxide (NO2) is a major constituent of the air pollution mix. Strong associations between NO2 and mortality have been identified in multicity studies around the world (Burnett et al. 2004; MacIntyre et al. 2014; Samoli et al. 2006; Tao et al. 2012). There is inconsistent evidence for a mechanistic driver of the effects of NO2 on health (Hesterberg et al. 2009); thus, it is unclear whether $\mathrm{NO} 2$ acts as an independent cause of mortality. Rather, there is consensus that NO2 could act as a proxy or surrogate species either for constituents that are not being monitored, or more generally for the multipollutant mix (Brook et al. 2007; Brunekreef and Holgate 2002; Levy et al. 2014). Thus, NO2 has been included in multipollutant health indices (Stieb et al. 2008) and is strictly monitored in some regions.

Given the robustness of NO2 as a predictor of the effects of air pollution on health, there is a great deal of interest in long-term estimates of historical concentrations. However, few regions, especially in developing countries, have collected sufficient observations for exposure assessment. In a few parts of the world, ground-station monitoring networks have operated for decades, providing a valuable record to evaluate satellite-based trends in air pollution.

Seltenrich (2014) summarized the opportunities offered by remote sensing for environmental health research in a recent Focus article in Environmental Health Perspectives. Novotny et al. (2011) and Vienneau et al. (2013) combined satellite data and land-use regression to calculate population-weighted mean NO2 over the United States in 2006 and over western Europe in 2005-2007. Novel applications have been found for such data in exploring disparities in exposure by socioeconomic factors (Clark et al. 2014). Observations of tropospheric NO2 vertical column densities from satellite instruments have provided evidence of dramatic changes over the United States (Duncan et al. 2013; Russell et al. 2012) and around the world (Hilboll et 
al. 2013; van der A et al. 2008). These results show the potential to document globally consistent changes in total atmospheric burden, but the observations have yet to be extended to long-term surface-level concentrations.

Global chemical transport models (CTMs) resolve atmospheric composition at a resolution of hundreds of kilometers horizontally by hundreds of meters vertically, with a temporal frequency of tens of minutes. Liu et al. (2004) first estimated surface-level PM2.5 from MISR observations by using CTM output to represent local aerosol optical depth (AOD)-PM2.5 conversion factors over the contiguous United States. van Donkelaar et al. (2006) extended the approach used by Liu et al. (2004) to estimate PM2.5 from both MODIS and MISR observations and investigated the factors affecting the agreement between AOD and surface-level PM2.5. Statistical models have also been used to relate AOD to PM2.5. For example, Liu et al. (2007) used MISR-retrieved spherical versus nonspherical particle fraction, in addition to model-derived vertical distribution, to separate mineral dust from other aerosol species. More recently, Paciorek and Liu (2009) probed the limitations of using AOD without accounting for vertical distribution or speciation and concluded that agreement with ground-based monitors based on this approach might depend on factors other than satellite observations.

Purpose of work is study remote sensing data for monitoring air quality in the territory of Ukraine.

The objectives is to study the experience of using RS application, fitness modern satellite systems and products for the analysis of air, establish mathematical relationships between satellite data and the results of ground-based observations, identify characteristics of distribution of air pollution in Ukraine.

The data from Project geoportals Atmospheric Composition Analysis Group (http://fizz.phys.dal.ca/) was used for the study. As the underlying data was selected studies using remote sensing content particles PM2.5 and nitrogen oxide NO2 as one of the basic types of air pollution.

\section{MAIN BODY OF TEXT}

\subsection{Materials and methods}

PM2.5 particles are smaller than 10 microns. There are two basic types of particles: they can be a carbon and metal, which in turn can be divided into divisions based on their magnetic properties. PM2,5 up 50-70\% PM10 in most territory of Europe. The particles can be anthropogenic and natural.

The current system of observations of the control air containing PM2.5 is exercised in Ukraine, which allows for the use of RS data for monitoring and forecasting the impact on health of the population.

Among all the nitrogen oxides in the atmosphere is mainly nitrogen dioxide $\mathrm{NO} 2$ - colorless poisonous gas that has no smell, irritating effect on the respiratory system. Nitrogen dioxide (NO2) formed in the ambient air as a result of oxidation of nitric oxide (NO), which in turn appears as naturally in the atmosphere and as a result of human activity. Nitrogen oxides are formed mainly by burning fossil fuels.

This is the result of chemical reactions between atmospheric N2 and $\mathrm{O} 2$ in the presence of heat to form NO, which then reacts with $\mathrm{O} 2$ to form $\mathrm{NO} 2$. The reaction rate is determined by the temperature of combustion. Especially dangerous nitrogen oxides in the cities where they interact with carbon and exhaust form photochemical fog - smog.

Nitrogen dioxide (NO2) plays an important role in the formation of tropospheric ozone and harmful to human health and ecosystems. So NO2 released in the troposphere as a result of anthropogenic (for example use of fossil fuels, burning biofuels, biomass) and natural (for example, forest fires and lightning) phenomena.

We used the $\mathrm{NO} 2$ pollution surveillance of the global ozone observation experiment (GOME), SCIAMACHY and GOME-2 satellite instruments (van Donkelaar et al., 2016). The calculation of the concentration of nitrogen dioxide surface (NO2) is through the use of local ratios with a global threedimensional model (GEOS-Chem) with the distribution of tropospheric NO2, received ozone layer monitoring tool (OMI) aboard the satellite Aura.

Ground PM2.5 data were calculated based on satellite sources through the use geographically weighted regression (GWR) for global estimates based on geophysical measurements. Data were obtained by PM2.5 the products of several satellites (Misr, MODIS Dark Target, MODIS and SeaWiFS Deep Blue, and MODIS MAIAC) combined with modeling (GEOS-Chem) based on their relative uncertainty as determined using terrestrial solar photometer (AERONET) (http://aeronet.gsfc.nasa.gov/).

Global resolved datasets are provided in ArcGIS-compatible NetCDF [.nc] or zipped ASCII [.asc.zip] file. Note that the unzipped ASCII files can be cumbersome. Gridded files use the WGS84 projection. The $0.01^{\circ} \times 0.01^{\circ}$ grid contains 12500 latitude coordinates, with centres from $54.995^{\circ} \mathrm{S}$ to $69.995^{\circ} \mathrm{N}$, and 36000 longitude coordinates, with centres from $179.995^{\circ} \mathrm{W}$ to $179.995^{\circ} \mathrm{E}$. The $0.1^{\circ} \times 0.1^{\circ}$ grid contains 1250 latitude coordinates, with centres from $54.95^{\circ} \mathrm{S}$ to $69.95^{\circ} \mathrm{N}$, and 3600 longitude coordinates, with centres from $179.95^{\circ} \mathrm{W}$ to $179.95^{\circ} \mathrm{E}$.

\subsection{The relationship between concentration NO2 and air pollution}

After downloading remote sensing data to PM2.5 and NO2 we was taken air pollution index (API) from the website of Central Geophysical Observatory (Ukraine). On the territory of Ukraine and the former Soviet Union to determine the state of air pollution using a composite index - API. When calculating API it takes into account not only the concentration of variogram substances, but their impact on human health.

This index is calculated for certain pollutants to assess the contribution of individual impurities in the general level of air pollution or for more complex substances to compare the degree of air pollution in different cities. Integrated API, which allows for $\mathrm{L}$ substances present in the atmosphere, calculated as follows:

$$
I_{n}=\sum_{i=1}^{n} L_{i}=\sum_{i=1}^{n}\left(x_{i} / M P C_{i}\right) C_{i}
$$

where $\mathrm{Xi}$ - annual average concentration of i-substance

$\mathrm{Ci}$ - coefficient that allows you to bring the degree of air pollution by i-matter to the extent of air pollution from sulfur dioxide, 
In - API, dimensionless.

MPCi - Maximum permissible concentration

Ci values determined for substances based on their hazard class. Nitrogen dioxide include the degree of hazard to the second hazard class $(\mathrm{Ci}=1)$, it provides all the harmful substances. $\mathrm{Ci}$ for substances 4, 3, 2 and 1 hazard classes which are equal to $0.85,1.0,1.3$ and 1.5 respectively.

The total API is used to compare the degree of air pollution in different cities, but this is only possible in case the measured concentration of the same set of agents. In practice, a set of measurable pollutants in different cities, moreover at different positions one city may vary. In this case, API is calculated for each substance, and this regressive variation range obtained values are summarize. With the value of API it can understand the degree of air pollution, pollution dynamics and the necessary management decisions in environmental management.

In this regard, the urgent task is to establish mathematical relationships between API and RS data available in order to be able to comparable estimates API data to the entire country.

As the input data it were used global indicators in the model estimated PM2.5 and NO2 in the period 1996-2014, which were presented as average, and as averaged over a period of time data.

Also, the study used data calculation API and its components for the period from 1992 to 2013, which were provided by the Central Geophysical Observatory for 53 settlements of Ukraine. As the basic software used software ArcGIS.

As a result, comparisons were established the presence of a significant relation between the data of satellite monitoring and $\mathrm{NO} 2$ values measured using instrumental tool. This indicates the effectiveness of the use of satellite data to evaluate air pollution to the entire country. The value of relationship increases in the direction of increasing absolute values of the indicator. In this case, the correlation coefficient is 0.8183 and is essential. The next step was to investigate the nature of the relationship between these. This was built distribution of settlements in two-dimensional space variogram where the $\mathrm{X}$ axis value delayed ground-based observations, and the axis $\mathrm{Y}$ satellite data (Fig. 1).

On the basis of this relationship linear regression equation has been calculated for the transition from data to results of groundbased observations of space survey:

$N O 2 e=1,23278021+0,498128761 * N O 2$,

where $N O 2 e$ - the estimated value of nitrogen dioxide, $\mathrm{NO} 2$ - primary satellite data measurement of nitrogen dioxide.

The value of $R 2=0,8183$ - that confirm the reliability of the model.

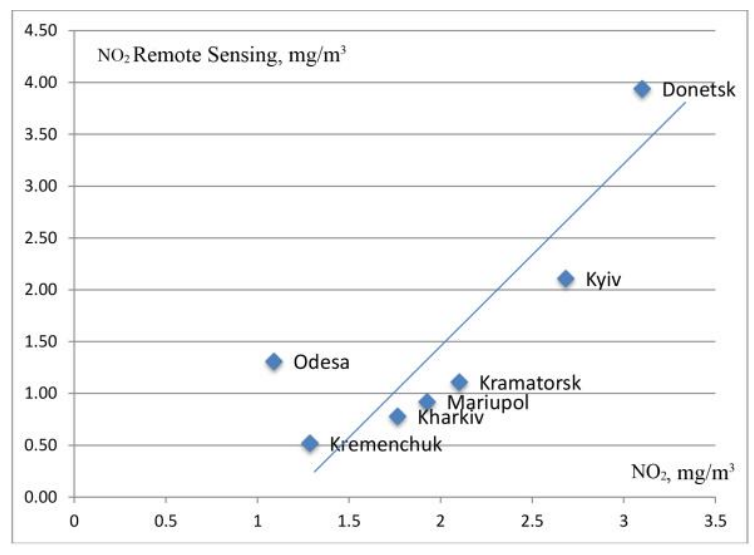

Figure 1. The relationship between ground observations data and remote sensing data $\mathrm{NO} 2$

This regression equation helps to get corrected NO2 value for the whole territory. Practical implementation of calculation was performed using raster calculator tool, which is part of the module Spatial Analyst. The result of calculation is shown in Fig. 2.

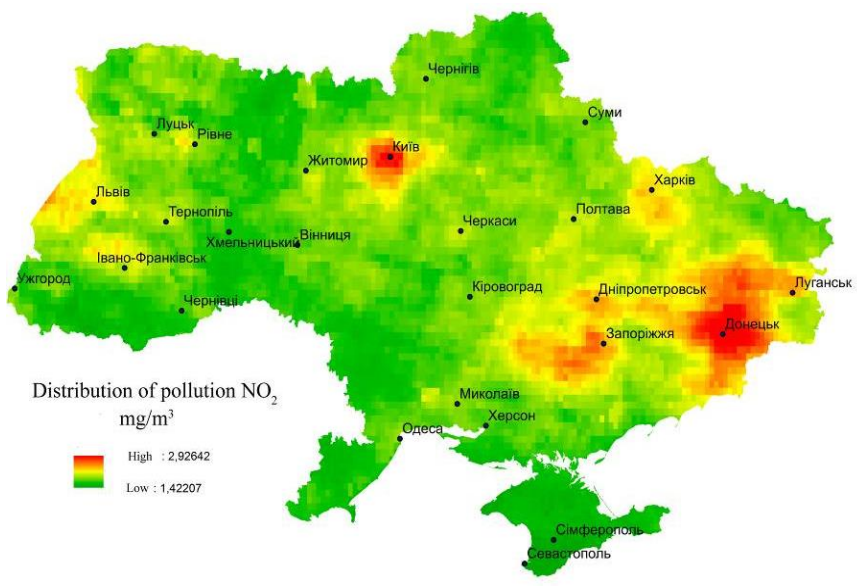

Figure 2. Correct with using research tool for value of measuring pollution $\mathrm{NO} 2$.

NO2 values map shows the highest values in eastern Ukraine, which is typical of industrial and developed regions. High values of pollution also clearly distinguished in the Dnieper basin, Zaporizhia, Kryvyi Rih. A major focus of NO2 emissions are Kyiv agglomeration and capital Kyiv, which affects up to $100 \mathrm{~km}$ on the air quality of the surrounding settlements. There remain major centers of Kharkiv, Ivano-Frankivsk, Lviv. In the latter case also affects cross-border moved.

The next step was research relationship individual indicators and integral API values. This was built variogram distribution between correct NO2 and API values (Fig. 3). 


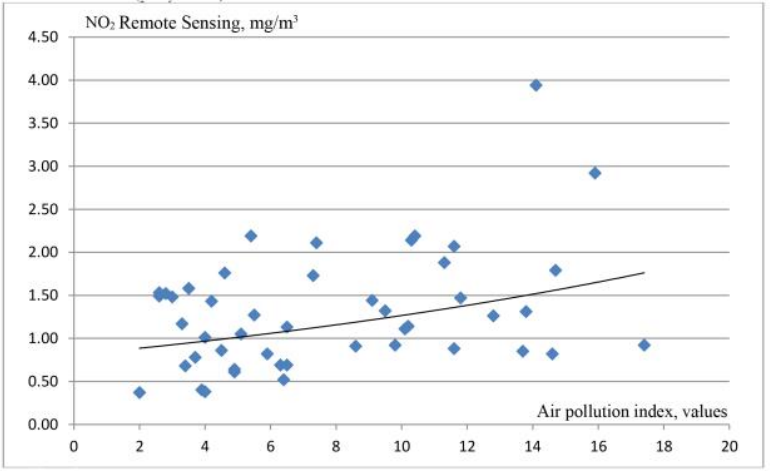

Figure 3. The relationship between the API data and NO2 pollution in the studied locations.

The analysis was proposed variogram exponential regression model using the following formula:

$A P I e=4,5464 * \operatorname{Exp}(0,2937 * N O 2 e)$,

where $A P I e$ - the estimated air pollution index

$N O 2 e$ - the estimated value of nitrogen dioxide have been derived from the transformation of primary satellite data.

The value of $R 2=0,6342$, which confirms the importance of the model.

Application exponential model promotes more rapid growth API values at a relatively low growth rate of NO2. In general, a distribution pattern corresponding to the deterioration of air quality in large cities.

\subsection{Regression models of PM 2.5 distribution}

The next step of our work was to determine the spatial relationships between indicators and PM 2.5. Fig. 4 shows that the largest concentration of particles PM2.5 observed in western Ukraine to $26 \mathrm{mg} / \mathrm{m} 3$ and is associated with moving to western Ukraine air masses and transboundary movement.

Total amplitude values in Ukraine ranges from 13 to $26 \mathrm{mg} / \mathrm{m} 3$, which indicates the change rate doubled. Other significant emission centers also have higher value. Only Kyiv agglomeration stands out far among them.

In this case, global and local methods used to establish relationship that provide for the availability of spatial differentiation coefficient regression equations.

Linear regression equation used as a global method:

$P M 2.5 e=17,4148+0,0023 * N O 2$,

where PM2.5e - the estimated value of PM 2.5 air pollution particles.

NO2 - nitrogen dioxide calculated value that was derived from the transformation of primary satellite data.

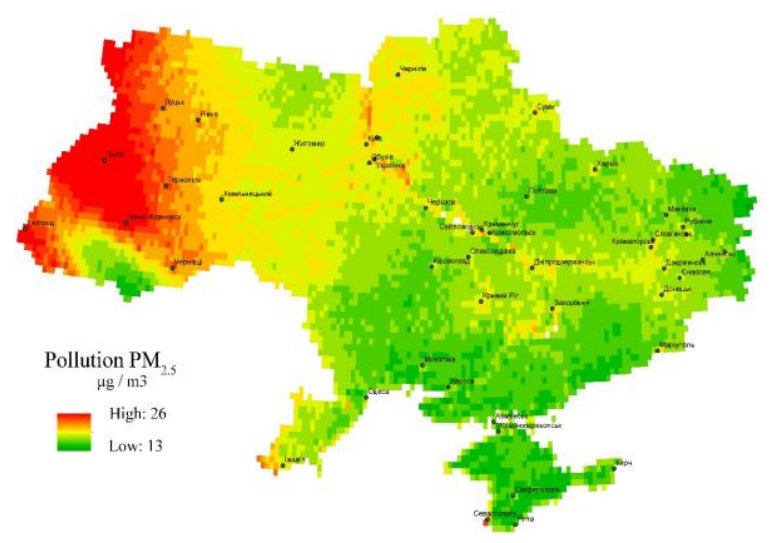

Figure 4. Distribution of average values of PM2.5 in Ukraine in 2012

Geographically weighted regression equation is:

$$
y_{i}=\beta_{0}\left(u_{i}, v_{i}\right)+\sum_{k=1}^{p} \beta_{k}\left(u_{i}, v_{i}\right) \cdot x_{i k}+\varepsilon_{i}
$$

where $\left(u_{i}, v_{i}\right)$ - location $i$ object (coordinates $i$ point);

$y_{i}$ - importance of effective characteristics;

$x_{i k}$ - value $k$ explanatory variables for $i$ object;

$\beta_{k}\left(u_{i}, v_{i}\right)$ - unknown coefficients;

$\varepsilon_{i}$ - regression remains;

$i=1,2 . ., n ; k=1,2, \ldots, p$.

The calculation results are geographically weighted regression for allocating PM2.5 depending on NO2 shown in Fig. 5. From this figure, you can see that the distribution of mean-square deviation has two regions: north, where important variations range from -0.433 to 0.246 , and the south, where appropriate range is marginal value: $0.247-0.937$. Thus, we can say that the majority of Ukraine enters the range, with a significant degree of confidence in the simulated global regression equation. At the same time, a clear separation of two areas in the country demonstrates the feasibility of two global or polynomial regression equations that will reduce the variance in their subregions.

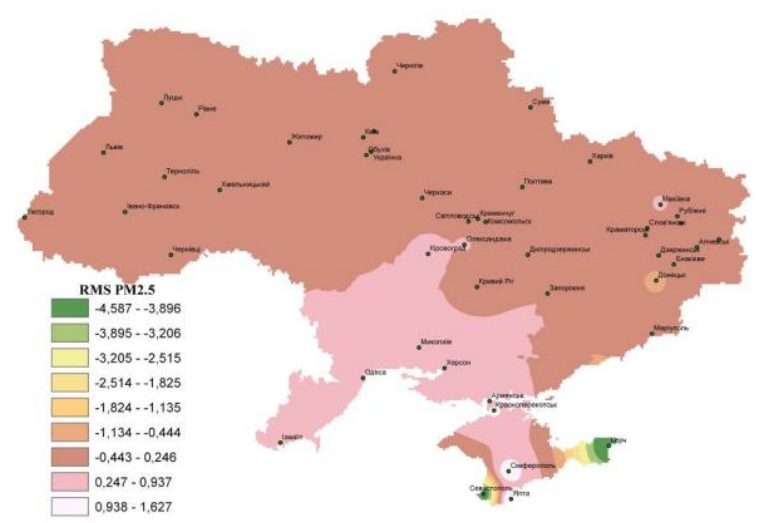

Figure 5. Distribution RMS deviation for geographically weighted regression PM2.5 


\section{CONCLUSION}

In the result of the work confirmed the feasibility of using remote sensing data and results processing for environmental assessment and monitoring of air. Based on research data it was found that the most representative indicators for assessing air quality measurement results is PM 2.5 and NO2. The dependence between ground observations and results processing satellite data to measure $\mathrm{NO} 2$ and nature of the relationship between NO2 and API, based on regression equations, which allows for the extrapolation of data on air quality in the entire territory of Ukraine, were established.

This makes it possible to conduct periodic air quality control for all localities, as well as to improve the ground-based observational network taking into account potential threats.

The indicators distress relationship between NO2 and PM 2.5 were established on the basis of methods geographically weighted regression that makes it possible to identify with reliable accuracy PM 2.5 values in some areas of Ukraine. However, it was found that allocation of PM 2.5 pollution differs significantly from traditional types of pollution, and therefore needs to develop its own terrestrial network control.

Perspectives of future research is to broaden the list of air pollutants studied using remote sensing data and calculation of integrated evaluation models for air pollution using remote sensing for support process of sustainable development.

\section{REFERENCES}

Aaron van Donkelaar, Randall V. Martin, Michael Brauer, N. Christina Hsu, Ralph A. Kahn, Robert C. Levy, Alexei Lyapustin, Andrew M. Sayer, and David M. Winker (2016) Global estimates of fine particulate matter using a combined geophysical-statistical method with information from satellites, models, and monitors. - Environ. Sci. Technol., 50 (7), pp 3762-3772. http://pubs.acs.org/doi/abs/10.1021/acs.est.5b05833

Brook JR, Burnett RT, Dann TF, Cakmak S, Goldberg MS, Fan $X$, et al. (2007). Further inter-pretation of the acute effect of nitrogen dioxide observed in Canadian time-series studies. J Expo Sci Environ Epidemiol 17(suppl 2):S36-S44.

Brunekreef B, Holgate ST. (2002). Air pollution and health. Lancet 360:1233-1242.

Burnett RT, Stieb D, Brook JR, Cakmak S, Dales R, Raizenne $\mathrm{M}$, et al. (2004). Associations between short-term changes in nitrogen dioxide and mortality in Canadian cities. Arch Environ Health 59:228-236.

Clark LP, Millet DB, Marshall JD. (2014). National patterns in environmental injustice and in-equality: outdoor $\mathrm{NO} 2$ air pollution in the United States. PLoS One 9:e94431.

Duncan BN, Yoshida Y, de Foy B, Lamsal LN, Streets DG, Lu Z, et al. (2013). The observed response of Ozone Monitoring Instrument (OMI) NO2 columns to NO x emission controls on power plants in the United States: 2005-2011. Atmos Environ 81:102-111.

Hesterberg TW, Bunn WB, McClellan RO, Hamade AK, Long CM, Valberg PA. (2009). Critical review of the human data on short-term nitrogen dioxide (NO2) exposures: evidence for NO2 no-effect levels. Crit Rev Toxicol 39:743-81.

Hilboll A, Richter A, Burrows JP. 2013. Long-term changes of tropospheric NO2 over megaci-ties derived from multiple satellite instruments. Atmos Chem Phys 13:4145-4169.

Kolesnik I.A., Kutsina N.A. (2015). Dynamics of air pollution in Ukraine. Proceedings of Central Geophysical Observatory, 25: 45 - 70. http://www.cgo.kiev.ua/index.php?fn=p\&f=files

Levy I, Mihele C, Lu G, Narayan J, Brook JR. (2014). Evaluating multipollutant exposure and urban air quality: pollutant interrelationships, neighborhood variability, and nitrogen diox-ide as a proxy pollutant. Environ Health Perspect 122:65-72.

Liu Y, Park RJ, Jacob DJ, Li QB, Kilaru V, Sarnat JA. (2004) Mapping annual mean ground-level PM2.5concentrations using multiangle imaging spectroradiometer aerosol optical thickness over the contiguous United States. J Geophys Res. 109:22206.

Liu Y, Koutrakis P, Kahn R. (2007) Estimating fine particulate matter component concentra-tions and size distribution using satellite-retrieved fractional aerosol optical depth: Part 1 method development. J Air Waste Manage Assoc. 57(11):13511359MacIntyre EA, Gehring U, Mölter A, Fuertes E, Klümper C, Krämer U, et al. (2014). Air pollution and respiratory infections during early childhood: an analysis of 10 European birth cohorts within the ESCAPE Project. Environ Health Perspect 122:107-13.

Novotny EV, Bechle MJ, Millet DB, Marshall JD. 2011. National satellite-based land-use re-gression: $\mathrm{NO} 2$ in the United States. Environ Sci Technol 45:4407-4414.

Paciorek CJ, Liu Y. (2009) Limitations of remotely-sensed aerosol as a spatial proxy for fine particulate matter. Environ Health Perspect. ;117:904-909.

Russell AR, Valin LC, Cohen RC. (2012). Trends in OMI NO2 observations over the United States: effects of emission control technology and the economic recession. Atmos Chem Phys 12:12197-12209.

Samoli E, Aga E, Touloumi G, Nisiotis K, Forsberg B, Lefranc A, et al. (2006). Short-term ef-fects of nitrogen dioxide on mortality: an analysis within the APHEA project. Eur Respir J 27:1129-1138.

Seltenrich N. (2014). Remote-sensing applications for environmental health research. Environ Health Perspect 122:A268-A275.

Stieb DM, Burnett RT, Smith-Doiron M, Brion O, Shin HH, Economou V. (2008). A new mul-tipollutant, no-threshold air quality health index based on short-term associations observed in daily time-series analyses. J Air Waste Manag Assoc 58:435-450.

Tao Y, Huang W, Huang X, Zhong L, Lu SE, Li Y, et al. (2012). Estimated acute effects of ambient ozone and nitrogen dioxide on mortality in the Pearl River Delta of southern China. Environ Health Perspect 120:393-398.] 
Putrenko V. and Tihohod V. "Geostatistical modelling of air pollution analysis", EasternEuropean Journal of Enterprise Technologies, vol. 4, No 10 (76), 2015, pp. 21-26.

van der A RJ, Eskes HJ, Boersma KF, van Noije TPC, Van Roozendael M, De Smedt I, et al. (2008). Trends, seasonal variability and dominant $\mathrm{NO} \times$ source derived from a ten year record of NO2 measured from space. J Geophys Res 113:D04302.

van Donkelaar A, Martin RV, Park RJ. (2006). Estimating ground-level PM2.5 using aerosol optical depth determined from satellite remote sensing. J Geophys Res. ;111:21201.
Vienneau D, de Hoogh K, Bechle MJ, Beelen R, van Donkelaar A, Martin RV, et al. (2013). Western European land use regression incorporating satellite- and ground-based measurements of NO2 and PM10. Environ Sci Technol 47:1355513564. 